\title{
A Memória Social do Estado Novo em Duas Gerações
}

Generational perspectives: Social memory during Getúlio Vargas dictatorship

\section{Denis Giovani Monteiro Naiff}

Universidade Federal Rural do Rio de Janeiro

Celso Pereira de Sá Universidade do Estado do Rio de Janeiro

Luciene Alves Miguez Naiff Universidade Salgado de Oliveira

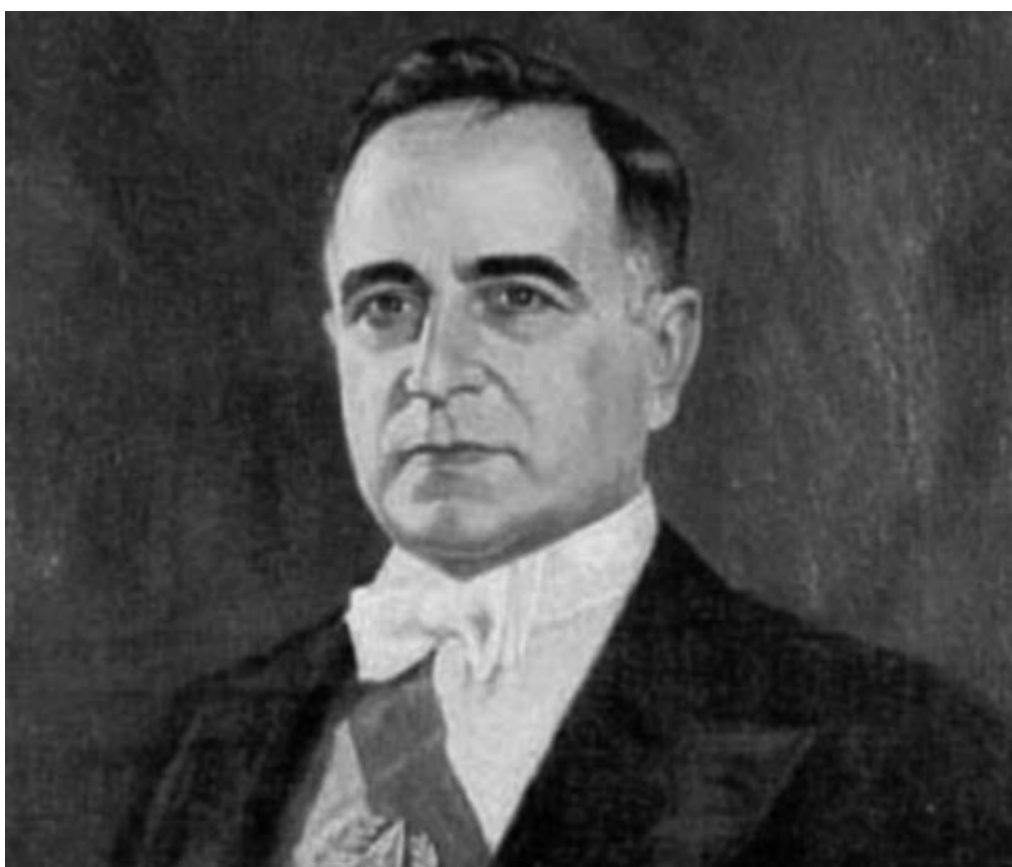


Resumo: No decorrer das últimas duas décadas, um bom número de perspectivas teóricas e de pesquisas empíricas tem procurado resgatar os aspectos psicossociais presentes na memória humana. O presente trabalho tem por objetivo descrever e comparar as memórias que duas diferentes gerações na população do Rio de Janeiro guardam sobre o período compreendido pela ditadura do Estado Novo. A amostra contou com 400 sujeitos, sendo 200 idosos e 200 adultos, aos quais foi aplicado um questionário que abordava diferentes aspectos do período supracitado. Os resultados mostram uma lembrança mais forte e detalhada do período na amostra idosa do que na adulta e nos sujeitos de nível educacional mais elevado e com orientação política definida. Conclui-se que os resultados corroboram a hipótese de que os acontecimentos políticos são mais retidos na memória da geração que os tenha testemunhado durante a juventude e principalmente por parte dos seus segmentos mais escolarizados e politizados.

Palavras-chave: Memória social. Memória geracional. Estado Novo. Ditadura.

\begin{abstract}
For the last two decades there has been a number of empirical research and theoretical perspectives with the main objective of capturing the psycho-social aspects of the human memory. This study describes and compares records of past events of two different generational groups in the city of Rio de Janeiro, Brazil, concerning Getulio Vargas's dictatorship period known as Estado Novo (1937-1945). The sample gathered 400 individuals, 200 elders and 200 adults. A questionnaire was used to approach different aspects about that historical period. The results show that the memory of that time is stronger and more detailed for the elders than for the adults, as well as for the subjects who had a higher level of education and defined political orientation.
\end{abstract}

Keywords: Social memory. Generation memory. Estado Novo. Dictatorship.

Os fenômenos mnemônicos parecem ter exercido um fascínio constante sobre o gênero humano. De fato, as preocupações com as dimensões sociais da memória humana surgiram na Grécia antiga e passaram por diferentes fases até o advento da imprensa e da revolução cultural que esta ensejou (Yates, 1992). Uma intensificação mais recente dessas preocupações é assim comentada por Jedlowski (2001):

No século $X X$, a memória foi assunto de consideráveis estudos nos campos da arte, da Filosofia e das ciências. As razões para essa especial atenção são prováveis de serem encontradas naquela peculiar construção cultural e social representada pela modernidade: de um lado, ela tem produzido um mundo em eterna mudança, na qual as tradições perdem seus valores e recorrentes descontinuidades são geradas; por outro lado, a modernidade tem oferecido cada vez mais instrumentos técnicos sofisticados que exteriorizam a faculdade humana de recordar e questionar seus significados. (p. 29)

Na Psicologia, durante décadas, a memória humana foi extensamente estudada apenas em seu aspecto individual. Entretanto, há algum tempo, tem-se observado nas ciências sociais um retorno do interesse pelo estudo das dimensões sociais e culturais presentes na memória humana. Esse interesse surge, inicialmente, no âmbito da Sociologia e da História e, mais recentemente, na Psicologia social (Bosi, 1979; Jodelet, 1991; Sá, 2005), principalmente através de releituras das idéias seminais do sociólogo francês Maurice Halbwachs (1925/1994. 1950/1990), do psicólogo inglês Frederic C. Bartlett (1932/1995) e, em menor escala, das idéias do psicólogo russo L. S. Vygotsky (Bakhurst, 1990, 2000; Vygotsky, 1984, ).

A preservação de um passado histórico na memória de uma população, bem 
O psicólogo russo Vygotsky (1984) acreditava que, mesmo nos estágios mais primitivos do desenvolvimento social, a memória humana poderia ser dividida em dois tipos básicos: uma memória natural e uma memória mediada. como a idéia da existência de uma cultura da memória, incluem-se nas temáticas privilegiadas nos estudos atuais. Isso permite, entre outras coisas, entender os mecanismos de construção e funcionamento da memória social, independentemente de esta ter sido formada na geração que testemunhou os acontecimentos, pela própria vivência, ou atualizada nas gerações que a sucederam (Sá \& Oliveira, 2002).

Foi no sentido de investigar a memória social de um período da história política brasileira construída e atualizada ao longo de meio século que se desenvolveu a tese de doutorado intitulada A memória social dos governos Vargas: um estudo comparativo entre duas gerações no Rio de Janeiro (Naiff, 2005) junto ao Programa de Pós-Graduação em Psicologia Social da UERJ. O presente artigo constitui um relato dos pressupostos teórico-conceituais e dos resultados parciais dessa pesquisa.

\section{As proposições clássicas sobre a memória social}

No campo da Psicologia social, o resgate da dimensão social presente na memória tem se centrado nas proposições seminais de Halbwachs, Bartlett e Vygotsky. Suas respectivas contribuições serviram de base para os estudos atuais, principalmente em relação aos aspectos que se seguem.

O sociólogo francês Halbwachs (1925/1994, 1950/1990), discípulo de Durkheim, propôs que toda memória individual poderia ser reduzida e explicada através da memória coletiva. As suas principais idéias podem ser resumidas da seguinte forma: (a) toda memória é social pelos seus conteúdos, pois sempre recordamos um mundo no qual existe a presença de outras pessoas; (b) a memória é social porque está apoiada nos "quadros sociais de referência", como os rituais, as cerimônias e os eventos sociais, entre outros; (c) a memória é social porque se baseia, principalmente, na linguagem e na comunicação lingüística externa e interna existente nos grupos.

O psicólogo inglês Bartlett (1932/1995) introduziu no estudo da memória social a noção de "convencionalização" social. Esta se refere aos processos pelos quais um sistema cultural ou um de seus elementos (um texto, uma imagem, uma idéia) é transformado quando é transferido de um grupo para o outro até tomar uma forma distinta, estável e aceita pelo grupo receptor em função de seu ajuste às técnicas e convenções estabelecidas há muito tempo dentro desse grupo. A lembrança se adapta, assim, às convenções (usos, costumes, valores, estereótipos) do grupo que as adota.

O psicólogo russo Vygotsky (1984) acreditava que, mesmo nos estágios mais primitivos do desenvolvimento social, a memória humana poderia ser dividida em dois tipos básicos: uma memória natural e uma memória mediada. A memória natural relaciona-se com a percepção sensorial e a atenção involuntária semelhante à existente nos outros tipos de animais, enquanto a memória mediada inclui a ação voluntária dos indivíduos no sentido de apoiar-se em elementos mediadores, signos e instrumentos que os ajudem a lembrar-se de conteúdos específicos.

\section{Algumas abordagens contemporâneas no estudo da memória social}

Uma boa parte dos estudos contemporâneos a respeito da memória social tem se concentrado em três linhas principais. A primeira trata de descrever como se constrói o passado social ou como ele é reconstruído em função das necessidades do presente, em especial, quando se definem as identidades nacionais e sociais. Nessa visão construtivista da memória, o passado é visto como parte de 
uma realidade que os psicólogos sociais, acompanhando Berger e Luckman (1997), consideram uma "construção social". A segunda linha busca analisar os fatores que influem para que certos acontecimentos sociais sejam retidos ou se percam dentro da memória social. Os acontecimentos são mais passíveis de serem recordados se são comemorados, se produzem um grande impacto emocional, se foram relevantes pessoalmente e se aconteceram durante a vida do indivíduo, principalmente entre a adolescência e os primeiros anos da vida adulta (Páez, Basabé, \& González, 1998). A terceira linha se propõe a identificar o que faz com que acontecimentos coletivos traumáticos, que não são comemorados, e são até negados institucionalmente, se mantenham como aspectos importantes da memória social. A tais acontecimentos, Pennebaker e Basanick (1998) chamaram de "acontecimentos silenciados". As ditaduras que existiram na América Latina e no sul da Europa seriam objetos adequados de estudos nessa linha.

Entendendo, com Jedlowski (1997), que, "de forma geral, a questão da memória coletiva é a necessidade de cada sociedade preservar sua própria herança cultural e passá-la de geração a geração" (p. 23), a transmissão intergeracional, ou seja, a forma pela qual as sociedades preservam a memória de um acontecimento através de sucessivas gerações, ganha relevância. Ainda a esse autor (Jedlowski, 2000) se deve a concepção da memória coletiva como um conjunto das representações sociais sobre o passado, o que autoriza a pesquisa da memória de fatos ou períodos históricos não testemunhados - ou mesmo escassamente transmitidos no âmbito de um dado conjunto social, que conta principalmente com recursos do próprio presente para a sua construção.

Empiricamente, o principal objetivo do presente artigo foi estudar a memória social que adultos e idosos residentes na cidade do Rio de Janeiro construíram a respeito do período histórico entre 1937 e 1945, durante o qual Getúlio Vargas governou o Brasil ditatorialmente e que entrou para a História com o nome de Estado Novo. Cabe ressaltar que, como os dados desta pesquisa foram coletados durante o ano 2004, quando os cinqüenta anos do suicídio de Getúlio eram objeto de eventos institucionais e análises rememorativas pela mídia, eles representam em grande parte uma memória socialmente atualizada daquele período.

\section{Método}

Sujeitos

A pesquisa foi realizada com 400 sujeitos moradores da cidade do Rio de Janeiro, divididos em dois subgrupos: (a) 200 sujeitos idosos que possuíam entre 15 e 21 anos durante os governos de Getúlio Vargas, ou seja, não menos que 65 anos, em 2004, e (b) 200 sujeitos adultos, que conhecem o regime Vargas através de fontes indiretas, como o ensino de História, os meios de comunicação de massa ou as conversas com os mais velhos.

Para a construção da amostra adulta, foi realizado um plano de amostragem em relação à população moradora da cidade do Rio de Janeiro que teria entre 34 e 60 anos em 2004. Além da idade, o plano de amostragem analisou a população quanto ao sexo e à escolaridade dos sujeitos.

O plano de amostragem dos sujeitos idosos foi construído levando-se em consideração a distribuição censitária da população acima de 60 anos moradora do Rio de Janeiro, descrita no site do Instituto Pereira Passos, da Prefeitura do Rio de Janeiro.

A Tabela 1 apresenta a distribuição das amostras quanto ao sexo, à escolaridade e à orientação política. Na variável sexo, observa- 
se alguma predominância do feminino sobre o masculino, mais acentuada no caso das mulheres idosas. Quanto à variável escolaridade, aproximadamente metade de cada uma das duas amostras estudou até o nível fundamental completo. A outra metade ficou dividida em partes praticamente iguais entre aqueles com ensino médio e aqueles com nível superior.

Quanto à orientação política dos sujeitos, mais da metade dos adultos e um pouco menos da metade dos idosos declaram-se sem orientação definida. Entre os idosos que fazem uma opção, aproximadamente $1 / 3$ se declaram de direita ou centro-direita, e $1 / 5$, de esquerda ou centroesquerda. Nos adultos, mesmo com valores menores, a relação se manteve, apresentando uma pequena predominância dos sujeitos que se declararam de direita ou centro-direita em relação aos que se declararam de esquerda ou centro-esquerda. É importante salientar que a variável "orientação política" não foi empregada no processo de construção da amostra a ser estudada.

Tabela 1: Distribuição das amostras segundo o sexo, a escolaridade e a orientação política dos sujeitos

\begin{tabular}{|c|c|c|c|}
\hline & & Adultos & Idosos \\
\hline \multirow{2}{*}{$\begin{array}{l}\stackrel{0}{\times} \\
\text { w }\end{array}$} & Masculino & $46 \%$ & $42 \%$ \\
\hline & Feminino & $54 \%$ & $58 \%$ \\
\hline \multirow{4}{*}{ 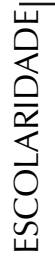 } & & & \\
\hline & Até o fundamental completo & $50 \%$ & $48 \%$ \\
\hline & Médio incompleto até completo & $27 \%$ & $27 \%$ \\
\hline & Superior incompleto até pós-graduação & $23 \%$ & $25 \%$ \\
\hline
\end{tabular}

\begin{tabular}{|c|c|c|c|}
\hline \multirow{3}{*}{ 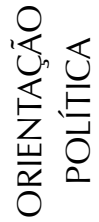 } & Direita e centro-direita & $25 \%$ & $34 \%$ \\
\hline & Esquerda e centro-esquerda & $16 \%$ & $20 \%$ \\
\hline & Sem orientação política & $59 \%$ & $46 \%$ \\
\hline
\end{tabular}

Coleta e análise dos dados

Foi aplicado aos sujeitos um questionário com questões fechadas e abertas sobre o período supracitado. Os dados relativos às questões fechadas e abertas foram alocados numa base de dados do programa Microsoft Excel e submetidos a análises estatísticas descritivas simples, na forma de freqüências e porcentagens.

\section{Resultados e discussão}

A memória do Estado Novo

O primeiro governo de Vargas não foi um período de democracia (Carvalho; 1999, Levine; 2001, Ribeiro, 2002, Skidmore, 1982). Desde a ascensão ao poder, em 1930, até o seu término, em 1945, o Brasil viveu, inicialmente, uma situação autoritária de fato, e, a partir da decretação do Estado Novo, em 1937, com a dissolução do Congresso Nacional e a outorga de uma nova 
Apesar de considerado menos violento que o regime de exceção que se instaurou mais tarde no Brasil - o Regime Militar (1954-

1985) -, o Estado Novo também se caracterizou por seguidas violações dos direitos humanos (Cancelli, 1994;

Carneiro, 1999;

Nasser, 1966).

$15 \%$ dos adultos e $40 \%$ dos idosos afirmam lembrar-

se da atuação da polícia política de Getúlio Vargas durante a vigência do Estado Novo.
Constituição (D'Araújo, 2000), o regime formalizou finalmente a implantação de uma ditadura de fato e de direito. As respostas das amostras para a pergunta sobre se eles se lembravam do que havia sido o chamado Estado Novo mostraram que 58\% dos idosos se lembravam de sua existência, contra apenas $14 \%$ dos adultos. As Tabelas 2 e 3 mostram a importância que a escolaridade e a orientação política declarada tiveram no registro e na manutenção do referido fato na memória.

Tabela 2: Percentual de sujeitos que relatam lembrar o que foi o chamado Estado Novo, segundo a escolaridade das amostras

\begin{tabular}{lll}
\hline & Adultos & Idosos \\
\hline Até o fundamental completo & $7 \%$ & $32 \%$ \\
Médio incompleto até médio completo & $15 \%$ & $69 \%$ \\
Superior incompleto até pós-graduação & $33 \%$ & $96 \%$ \\
\hline
\end{tabular}

Nos adultos, cuja lembrança geral é mais baixa, os resultados praticamente dobram entre cada classe de escolaridade selecionada (tabela 2). De $7 \%$ das respostas dos sujeitos com baixa escolaridade que relatam lembrar-se do Estado Novo, chega-se a praticamente 1/3 daqueles com alta escolaridade. $\mathrm{Na}$ amostra idosa, os resultados também praticamente dobram entre os sujeitos com baixa e com média escolaridade (de 32\% para 69\%), atingindo quase a universalidade dos sujeitos com escolaridade alta (96\%).

Em relação à orientação política (Tabela 3), os resultados apontam diferenças significativas na lembrança do Estado Novo entre os que declaram ter algum posicionamento e os que não o têm. Para a população idosa, essa diferença chega a ser multiplicada por quatro, independentemente da opção declarada (direita ou esquerda), ou seja, a lembrança do Estado Novo aparece diretamente influenciada pelo interesse ou envolvimento dos sujeitos com as questões políticas. Nos adultos, mesmo com diferenças menos pronunciadas, também os sujeitos sem orientação política são os que menos se lembram do Estado Novo (7\%), enquanto os que se declaram de esquerda ou centro-esquerda se lembram mais dele (24\%) do que os de direita e centro-direita (15\%).

Tabela 3: Percentual de sujeitos que relatam lembrar o que foi o chamado Estado Novo, segundo a orientação política declarada

\begin{tabular}{lll}
\hline & Adultos & Idosos \\
\hline Direita e centro-direita & $15 \%$ & $81 \%$ \\
Esquerda e centro-esquerda & $24 \%$ & $82 \%$ \\
Sem orientação política & $7 \%$ & $28 \%$ \\
\hline
\end{tabular}

A memória da polícia política de Getúlio Vargas durante o Estado Novo

Apesar de considerado menos violento que o regime de exceção que se instaurou mais tarde no Brasil - o Regime Militar (1954-1985) -, o Estado Novo também se caracterizou por seguidas violações dos direitos humanos (Cancelli, 1994, Carneiro, 1999, Nasser, 1966). 15\% dos adultos e $40 \%$ dos idosos afirmam lembrar-se da atuação da polícia política de Getúlio Vargas durante a vigência do Estado Novo. 
Entre os sujeitos que se lembram, mais de $60 \%$ das duas amostras relatam que a polícia política do primeiro governo era repressora e violenta. Para $24 \%$ dos adultos, a atuação policial podia ser classificada de bem severa, porém sem característica explicita de violência ou crueldade. Uma avaliação positiva da atuação policial é obtida em apenas $10 \%$ das duas amostras.

Merece destaque a objetivação feita pela amostra idosa da violência ocorrida no Estado Novo. Diferentemente do Regime Militar instalado em 1964, cujas violações de direitos humanos foram, em parte, fruto de uma anarquia militar reinante nos quartéis (Gaspari, 2002a, 2002b, 2003), o que acabou por dificultar a personificação do torturador em uma única figura, no Estado Novo, essa personificação aparece na memória de $21 \%$ dos sujeitos que viveram o período na figura do chefe da polícia política de Vargas, Filinto Müller.

A memória de Getúlio Vargas enquanto ditador

A resposta à questão se Vargas havia sido um ditador - ao que se acrescentavam os adjetivos autoritário e repressor, como tem sido a grande maioria dos ditadores merece uma análise cuidadosa. Os resultados apontam uma divisão tanto nos idosos quanto nos adultos a respeito da imagem de Vargas enquanto ditador autoritário e repressor. Para os idosos, 44\% se lembram de que Getúlio foi um ditador com essas características (que, no restante deste relato, serão mantidas implícitas), $30 \%$ que não o foi, e $26 \%$ declaram não se lembrar do assunto. Nos adultos, encontram-se $41 \%$ que associam à figura de Vargas o epíteto de ditador, $47 \%$ que não o fazem e $12 \%$ que alegam não se lembrar.

É importante também ressaltar que, mesmo de forma discreta, os idosos se lembram mais de Vargas como ditador, enquanto os adultos o lembram como não tendo sido. Para entender melhor a distribuição das respostas nas duas amostras, resolveu-se analisá-las em função da escolaridade e da orientação política dos sujeitos.

Quanto à escolaridade (Tabela 4), os resultados apontam uma relação proporcionalmente direta entre essa variável e a lembrança do assunto. Entre os idosos, o percentual dos que consideram que Vargas tenha sido um ditador aumenta de 13\% naqueles com baixa escolaridade para $80 \%$ naqueles com alta escolaridade. Entre os que não o vêem como um ditador, a relação se inverte: de $42 \%$ com baixa escolaridade, cai para $20 \%$ conforme aumenta a faixa de escolaridade. Enquanto na amostra com baixa escolaridade $45 \%$ dos sujeitos relatam não saberem responder à questão, naquela com alta escolaridade a totalidade dos sujeitos se posiciona a esse respeito.

Apesar de não serem tão discriminantes quanto no caso dos idosos, os resultados relativos aos adultos destacam o fato de que aqueles com alta escolaridade se lembram mais de Vargas ter sido um ditador, enquanto os de baixa e média escolaridade se lembram do contrário.

Tabela 4: Distribuição das respostas das amostras para a lembrança de Getúlio Vargas haver sido ou não um ditador autoritário e repressor, segundo a escolaridade dos sujeitos

\begin{tabular}{|c|c|c|c|}
\hline & \multicolumn{2}{|c|}{ Adultos } & Idosos \\
\hline \multirow{3}{*}{$\begin{array}{l}\text { Até o fundamental } \\
\text { completo }\end{array}$} & Sim & $40 \%$ & $13 \%$ \\
\hline & Não & $50 \%$ & $42 \%$ \\
\hline & Não sei & $10 \%$ & $45 \%$ \\
\hline & Sim & $32 \%$ & $66 \%$ \\
\hline \multirow{2}{*}{ até médio completo } & Não & $53 \%$ & $19 \%$ \\
\hline & Não sei & $15 \%$ & $15 \%$ \\
\hline \multirow{3}{*}{$\begin{array}{l}\text { Superior incompleto } \\
\text { até pós-graduação }\end{array}$} & Sim & $54 \%$ & $80 \%$ \\
\hline & Não & $35 \%$ & $20 \%$ \\
\hline & Não sei & $11 \%$ & $0 \%$ \\
\hline
\end{tabular}


Quando se volta para a orientação política declarada pelas amostras, os resultados presentes na Tabela 5 mostram que nos idosos a lembrança é extremamente similar entre os que declaram ter alguma orientação política, com $69 \%$ dos sujeitos, tanto de esquerda quanto de direita, lembrandose da figura de Getúlio como ditador. A maioria dos que não possui orientação política declara não saber se posicionar a respeito do assunto. Pode-se convir aqui que, embora a lembrança do Estado Novo tenha sido registrada originalmente quando aqueles primeiros sujeitos ainda eram muito jovens, a consciência política que tinham já então - ou que desenvolveram ao longo de suas vidas - responda pela construção da memória daquele período como uma ditadura. Não importa aqui que essa lembrança possa estar, em diferentes sujeitos, associada a uma execração ou a uma admiração, visto que àquela época histórica não era incomum o fato de os regimes de força serem reconhecidos em grande parte do mundo, pela direita e pela esquerda, como regimes relacionados à eficiência e ao desenvolvimento.

Nos adultos, ao contrário, as principais diferenças são encontradas entre os que declaram ter alguma orientação política. Para a maioria dos que se consideram de direita ou centro-direita, Vargas não foi um ditador, enquanto, para os de esquerda ou centro-esquerda, a relação se inverte, com a maioria considerando que ele tenha sido um ditador. Esses resultados parecem indicar que os herdeiros mais plausíveis do trabalhismo, os que se definem no espectro político de esquerda, são, em uma segunda geração, os que menos esquecem - provavelmente lamentando - o passado autoritário de Getúlio Vargas, enquanto a amostra que se define como de direita - orientação política conhecida pelas críticas ao modelo de desenvolvimento que entrou para a história com o nome de "Era Vargas" (D’Araújo, 1997)
- parece ter tido esse dado - possivelmente secundário - esvaecido da sua memória.

Ainda quanto aos adultos, as hipóteses geracionais da memória social dão margem a uma interpretação adicional. Essa geração possui, entre outras, uma peculiaridade: viveu, em diferentes graus de intensidade, o Regime Militar pós 1964 na sua idade crítica, ou seja, entre a adolescência e o início da idade adulta (Conway, 1990). Esse foi um período especialmente difícil para os que eram classificados politicamente como de esquerda, não se excluindo mesmo a parcela mais jovem da população, o que pode ter levado esses sujeitos a, na construção da sua memória ou representação social de uma ditadura não experimentada, ancorarem na memória uma ditadura efetivamente vivida, com toda a sua carga de autoritarismo e repressão.

Tabela 5: Distribuição das respostas das amostras para a lembrança de Getúlio Vargas haver sido ou não um ditador autoritário e repressor, segundo a orientação política dos sujeitos

\begin{tabular}{llll}
\hline & & Adultos & Idosos \\
\hline Direita e & Sim & $39 \%$ & $69 \%$ \\
centro-direita & Não & $57 \%$ & $25 \%$ \\
& Não sei & $4 \%$ & $6 \%$ \\
Esquerda e & Sim & $58 \%$ & $69 \%$ \\
centro-esquerda & Não & $30 \%$ & $26 \%$ \\
& Não sei & $12 \%$ & $5 \%$ \\
Sem orientação & Sim & $37 \%$ & $9 \%$ \\
política & Não & $50 \%$ & $37 \%$ \\
& Não sei & $13 \%$ & $54 \%$ \\
\hline
\end{tabular}

A memória de acontecimentos ocorridos no decorrer do Estado Novo

A violação de direitos fundamentais da pessoa humana e a restrição das liberdades pessoais são ações que, em algum grau, costumam 
Nos idosos, as respostas para o fechamento do Congresso Nacional, para a censura da imprensa e das artes e para o cerceamento das liberdades pessoais encontram-se divididas entre os que se lembram que os fatos ocorreram no período e os que relatam não se lembrarem. acompanhar a rotina dos regimes de exceção. À vista disso, perguntou-se às duas amostras qual a lembrança que guardam dos fatos ocorridos durante o Estado Novo, mais especificamente, se se lembravam de terem ocorrido: (a) cassação de mandatos e direitos; (b) fechamento do Congresso Nacional; (c) censura da imprensa e das artes; (d) tortura e morte de presos políticos; (e) cerceamento de liberdades pessoais.

Os resultados são apresentados na Tabela 6, e revelam, na média, que os idosos lembram mais que os fatos relatados acima aconteceram durante a vigência do Estado Novo. Nos adultos, a maioria das respostas indica a ausência de lembrança em relação a esses fatos, com exceção da cassação de mandatos e direitos e da tortura e morte de presos políticos, que a maioria das respostas indica terem acontecido durante o período.

Nos idosos, as respostas para o fechamento do Congresso Nacional, para a censura da imprensa e das artes e para o cerceamento das liberdades pessoais encontram-se divididas entre os que se lembram que os fatos ocorreram no período e os que relatam não se lembrarem. Sobre esses fatos, aproximadamente metade da amostra adulta relata não se lembrar de terem acontecido ou não no período.

Tabela 6: Distribuição das respostas das amostras para a lembrança de fatos supostamente ocorridos durante a ditadura do Estado Novo

\begin{tabular}{|c|c|c|c|}
\hline & & Adultos & Idosos \\
\hline \multirow[t]{3}{*}{ Cassação de mandatos e direitos } & Aconteceu & $45 \%$ & $50 \%$ \\
\hline & Não aconteceu & $18 \%$ & $10 \%$ \\
\hline & Não lembra & $37 \%$ & $40 \%$ \\
\hline \multirow[t]{3}{*}{ Fechamento do Congresso Nacional } & Aconteceu & $28 \%$ & $49 \%$ \\
\hline & Não aconteceu & $23 \%$ & $4 \%$ \\
\hline & Não lembra & $49 \%$ & $47 \%$ \\
\hline \multirow[t]{3}{*}{ Censura da imprensa e das artes } & Aconteceu & $38 \%$ & $46 \%$ \\
\hline & Não aconteceu & $17 \%$ & $8 \%$ \\
\hline & Não lembra & $45 \%$ & $46 \%$ \\
\hline \multirow[t]{3}{*}{ Tortura e morte de presos políticos } & Aconteceu & $45 \%$ & $49 \%$ \\
\hline & Não aconteceu & $22 \%$ & $9 \%$ \\
\hline & Não lembra & $33 \%$ & $42 \%$ \\
\hline \multirow[t]{3}{*}{ Cerceamento de liberdades pessoais } & Aconteceu & $31 \%$ & $49 \%$ \\
\hline & Não aconteceu & $18 \%$ & $9 \%$ \\
\hline & Não lembra & $51 \%$ & $42 \%$ \\
\hline
\end{tabular}

A relação entre a memória dos fatos supracitados e a escolaridade dos sujeitos idosos pode ser mais bem vista na Figura 1. Como se pode observar, independentemente do fato em questão, a proporção dos sujeitos que viveram aquele período histórico entre a adolescência e o começo da idade adulta e que informam se lembrar do acontecimento durante tal período aumenta conforme a escolaridade também aumenta, o que faz sugerir a hipótese de que esse seja um fator 
fundamental no registro dos fatos ocorridos - através da leitura de jornais à época, por exemplo - e na construção social da memória do Estado Novo - através das análises empreendidas em grupos familiares e com os pares.

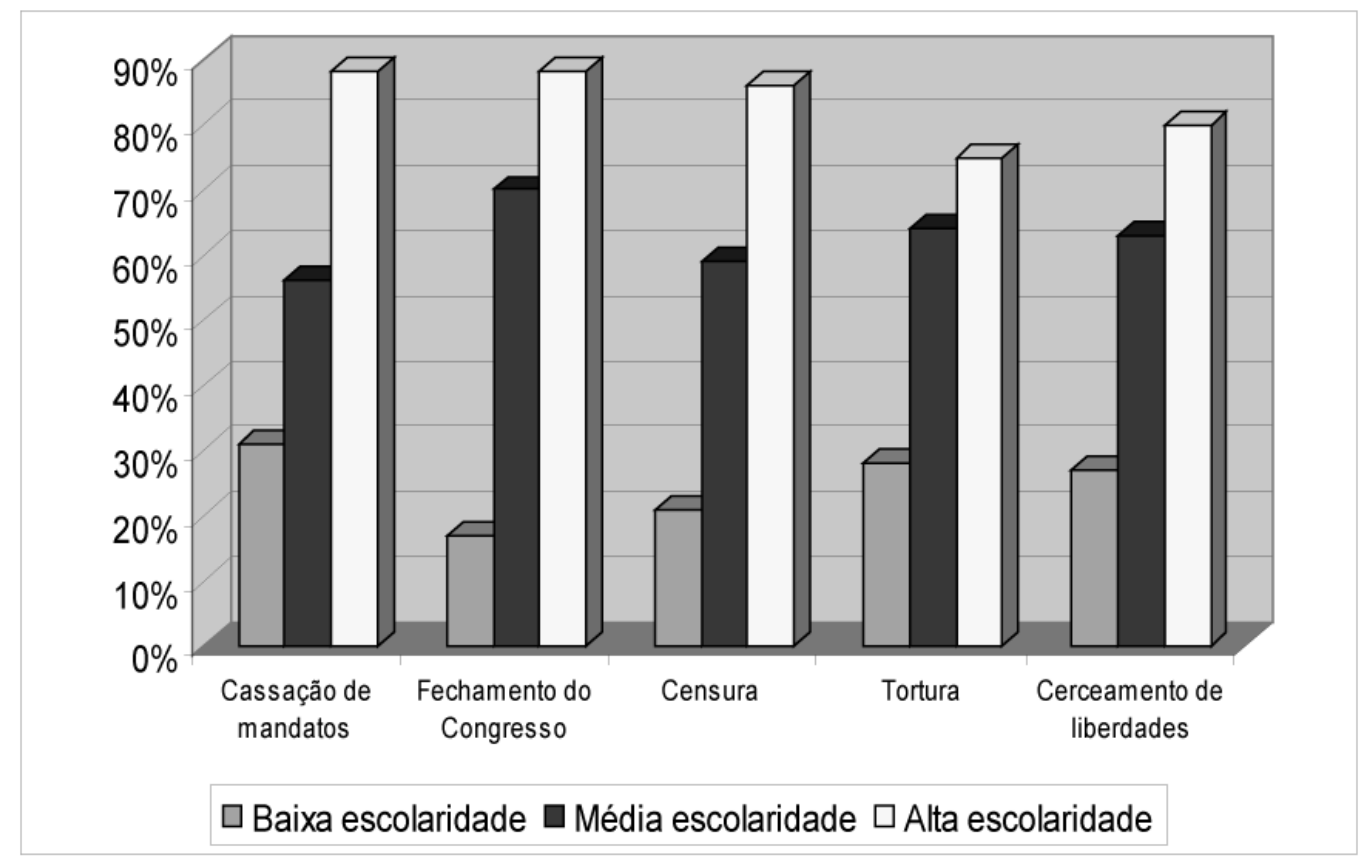

Figura 1: Comparação entre a escolaridade dos sujeitos idosos e o resultado de suas lembranças para a ocorrência dos fatos na vigência do Estado Novo

\section{Conclusões}

Tornou-se comum dizer que o Brasil é um país sem memória, principalmente quando nos referimos às memórias relativas aos fatos políticos. Essa é uma afirmação que, de tanto ser repetida, parece ter incorporado ares de veracidade, como se houvesse um desejo institucional na sociedade brasileira de se esquecer que se sobreponha às necessidades individuais de se lembrar de determinados acontecimentos.

Porém, um olhar atento sobre as lembranças encontradas neste trabalho parece indicar justamente o contrário: a lembrança da figura de Getúlio Vargas e dos acontecimentos do Estado Novo permanece presente em parcelas das duas amostras. Ela se apresenta com maior intensidade nas populações que puderam testemunhar os acontecimentos, ou seja, os idosos, ressaltando a importância que a vivência de um determinado fato tem na magnitude e, possivelmente, na qualidade da memória construída sobre acontecimentos ocorridos dentro de um período histórico determinado. A geração subseqüente ao período só pôde acessar a informação através de formas indiretas de apreensão desse conhecimento, como a educação escolar, os meios de comunicação de massa, as trocas familiares de experiência, etc. Nesse aspecto, há de se lamentar a condição de 
A relação direta existente entre a escolaridade dos sujeitos e a manutenção dos conteúdos políticos na memória social da população apareceu de forma clara e inequívoca tanto na amostra dos idosos quanto na dos adultos. exclusão a que muitas vezes estão relegados os estratos mais idosos da nossa sociedade, o que priva as gerações mais novas de ouvirem as histórias de vida de seus avós.

Os resultados apresentados em um trabalho anterior (Naiff e Sá, 2005) salientaram a existência de uma positividade na memória social da figura política de Getúlio Vargas, tanto entre os sujeitos idosos quanto entre os adultos, e deixaram em um plano secundário o passado autoritário e a história de repressão política de seu primeiro governo. Nesse sentido, no presente trabalho, observou-se que menos da metade das amostras relatam lembrar-se de Vargas enquanto ditador autoritário e repressor, e apenas $40 \%$ dos idosos e 15\% dos adultos relatam lembrar a atuação violenta da polícia política no Estado Novo. Isso parece corroborar as conclusões de estudos anteriores (Deschamps, Páez, \& Pennebaker, 2002; Páez, Valencia, Basabé, Herranz, \& González, 2000), que revelam o fato de os passados mais remotos se tornarem menos negativos na memória social conforme a linha do tempo avança.

A relação direta existente entre a escolaridade dos sujeitos e a manutenção dos conteúdos políticos na memória social da população apareceu de forma clara e inequívoca tanto na amostra dos idosos quanto na dos adultos. Nesse caso, a escolaridade parece agir como uma espécie de fator adicional na permanência dos elementos mnemônicos, possivelmente refletindo um testemunho mais acurado dos fatos pelos sujeitos quando de sua ocorrência, através das leituras de jornais e do compartilhamento das informações através das conversas nos grupos de pertencimento. Assim, possivelmente através de uma disposição constante para se informar, prática mais comum nos estratos com maior escolaridade na população, os sujeitos freqüentemente estariam expostos a uma gama de informações que atuariam atualizando constantemente as suas memórias, principalmente quando nos referimos aos eventos mais remotos.

A ausência de uma orientação política declarada em uma parte dos sujeitos das duas amostras, mais do que sua orientação política à direita ou à esquerda, também parece afetar a intensidade e a qualidade das lembranças evocadas sobre o período estudado. Refletindo a relação entre a escolaridade e a orientação política nos sujeitos, observamos que, entre os sujeitos que declaram não ter orientação política, 63\% dos adultos e $76 \%$ dos idosos possuem no máximo escolaridade fundamental completa, e apenas $9 \%$ dos adultos e $6 \%$ dos idosos têm escolaridade superior.

Finalizando, a descrição e a comparação intergeracional das lembranças de fatos relacionados ao Estado Novo mostra que, contrariamente a uma noção genericamente difundida, o povo brasileiro tem, sim, memória. Trata-se de uma memória que está, como a de todos os outros povos, submetida ao paradoxo que lhe é inerente, e que Jedlowski (2001) assim resume: "O passado estrutura o presente através de seus legados, mas é o presente que seleciona esses legados, preserva alguns aspectos e esquece outros, o que constantemente reformula nossas imagens do passado pela recontagem da História" (p. 41). 
Denis Giovani Monteiro Naiff - Doutor em Psicologia social pela Universidade do Estado do Rio de Janeiro (UERJ); Professor adjunto do Departamento de Psicologia da Universidade Federal Rural do Rio de Janeiro (URRJ). E-mail: dnaiff@ufrj.br

Celso Pereira de Sá - Doutor em Psicologia social pela Fundação Getúlio Vargas (FGV); Professor titular do Instituto de Psicologia da Universidade do Estado do Rio de Janeiro (UERJ).

E-mail: as.celso@gmail.com

Luciene Alves Miguez Naiff - Doutora em Psicologia social pela Universidade do Estado do Rio de Janeiro (UERJ); Professora titular do Mestrado em Psicologia da Universidade Salgado de Oliveira (UNIVERSO).

E-mail: lunaiff@hotmail.com

Endereço para correspondência:

Rua Conselheiro Olegário, no 34, ap. 103 - Maracanã Cep: 20271-090, Rio de Janeiro-RJ.

Recebido 15/03/07 Reformulado 11/06/07 Aprovado 16/06/07

Referências
Bakhurst, D. (1990). Social memory in Soviet thought. In D. Middleton \& D. Edwards (Eds.), Collective remembering (pp. 203-226). London: Sage.

Bakhurst, D. (2000). Memoria, identidad y psicología cultural. In A. Rosa, G. \& Bellelli, D. Bakhurst (Eds.), Memoria colectiva e identidad nacional (pp. 91-106). Madrid: Biblioteca Nueva.

Bartlett, E. C. (1995). Remembering: A study in experimental and Social Psychology. Cambridge: Cambridge University Press. (Trabalho original publicado em 1932)

Berger, P. I., \& Luckman, T. (1997). A construção social da realidade. Petrópolis RJ: Vozes.

Bosi, E. (1979). Memória e sociedade: lembranças de velhos. São Paulo: T. A. Queiroz.

Cancelli, E. (1994). O mundo da violência: a polícia da Era Vargas. Brasília: Editora da UnB.

Carneiro, M. L. T. (1999). O Estado Novo, o Dops e a ideologia da segurança nacional. In D. Pandolfi (Ed.), Repensando o Estado Novo (pp. 327-340). Rio de Janeiro: Editora da FGV.

Carvalho, J. M. (1999). Vargas e os militares: aprendiz de feiticeiro. In M. C. D'Araújo (Org.), As instituições brasileiras da era Vargas (pp. 55-81). Rio de Janeiro: EDUERJ/FGV.

Conway, M. A. (1990). Associations between autobiographical memories and concepts. Journal of Experimental Psychology: Learning, Memory, and Cognition, 16(5), 799-812.

D’Araújo, M. C. (1997). A era Vargas. São Paulo: Moderna.

D’Araújo, M. C. (2000). O Estado Novo. Rio de Janeiro: Jorge Zahar.

Deschamps, J. C., Paez, D., \& Pennebaker, J. (2002). Mémoire collective et histoire à la fin du second millénaire. In S. Laurens \& N. Roussiau (Eds.), La mémoire sociale: identités et représentations sociales. (pp.245-258). Rennes: Presses Universitaires de Rennes.

Gaspari, E. (2002a). A ditadura envergonhada. São Paulo: Companhia das Letras.

Gaspari, E. (2002b). A ditadura escancarada. São Paulo: Companhia das Letras.

Gaspari, E. (2003). A ditadura derrotada. São Paulo: Companhia das Letras.

Halbwachs, M. (1990). A memória coletiva. São Paulo : Vértice. (Trabalho original publicado em 1950)

Halbwachs, M. (1994). Les cadres sociaux de la mémoire. Paris: Albin Michel. (Trabalho original publicado em 1925)

Jedlowski, P. (1997). Colletive memories. In Small-Group Meeting on Collective Memory (pp. 23-30). Bari: Proceedings.

Jedlowski, P. (2000). La Sociología y la memoria colectiva. In D. Páez, J.F. Valencia, J. W. Pennebaker, B.Rimé, \& D. Jodelet (Eds.), Memorias colectivas de procesos culturales y políticos (pp.123-134). Bilbao: Universidad del País Vasco.
Jedlowski, P. (2001). Memory and sociology: Themes and issues. Time \& Society, 10(1), 29-44.

Jodelet, D. (1992). Mémoire de masse: le côté moral et affective de Phistoire. Bulletin de Psychologie, XLV(405), 239-256.

Levine, R. M. (2001). Pai dos pobres: o Brasil e a era Vargas. São Paulo: Companhia das Letras.

Naiff, D. G. M. (2005). A memória social dos governos Vargas: um estudo comparativo entre duas gerações no Rio de Janeiro. 188f. Tese de Doutorado em Psicologia social, Universidade do Estado do Rio de Janeiro, Rio de Janeiro.

Naiff, D. G. M., \& Sá, C. P. (2005). Os governos Vargas nas representações sociais e memórias de duas gerações do Rio de Janeiro. In IV Jornada Internacional e II Conferência Brasileira sobre Representações Sociais. Textos completos. João Pessoa, Editora da UFPB.

Nasser, D. (1966). Falta alguém em Nuremberg: torturas da polícia de Filinto Müller. Rio de Janeiro: Edições O Cruzeiro.

Páez, D., Basabé, N., \& González, J. L. (1998). Memoria colectiva y traumas políticos: investigación transcultural de los procesos sociales del recuerdo de sucesos políticos traumáticos. In D. Páez, J.F. Valencia, J. W. Pennebaker, B. Rimé \&, D. Jodelet (Eds.), Memorias colectivas de procesos culturales y políticos (p. 171). Bilbao: Universidad del País Vasco.

Páez, D., Valencia, J., Basabé, N., Herranz, K. \& González, J. L. (2000). Identidad, comunicación y memoria colectiva. In A. Rosa, G. Bellelli, \& D. Bakhurst (Eds.), Memoria colectiva e identidad nacional. (pp. 385-412). Madrid: Biblioteca Nueva.

Pennebaker, J. W. \& Basanick, B. (1998). Creación y mantenimiento de memorias coletivas. In D Páez, J. F. Valencia, J.W. Pennebaker, B. Rimé, \& D. Jodelet (Eds.), Memorias colectivas de procesos culturales y políticos (pp. 31-48). Bilbao: Universidad del País Vasco.

Ribeiro, J. A. (2000). A era Vargas: o primeiro governo Vargas. Rio de Janeiro: Casa Jorge Editorial.

Sá, C. P. (2005). As memórias da memória social. In C. P. Sá (Ed.), Memória, imaginário e representações sociais (pp. 63-86). Rio de Janeiro: Museu da República.

Sá, C. P., \& Oliveira, D. C. (2002). Sur la mémoire sociale de la découverte du Brésil. In S. Laurens \& N. Roussiau (Eds.), La mémoire sociale: Identités et représentations sociales (pp. 107118). Rennes: Presses Universitaires de Rennes.

Skidmore, T. (1982). Brasil: de Getúlio a Castelo. Rio de Janeiro: Paz e Terra.

Vygotsky, L. S. (1984). A formação social da mente. São Paulo: Martins Fontes.

Yates, F. A. (1992). The art of memory. London: Pmilico. 